\title{
MUSEU MUNICIPAL ATÍLIO ROCCO
}

\author{
Luciano Chinda Doarte ${ }^{1}$ \\ Vitor Magliocco do Carmo ${ }^{2}$ \\ Gladisson Silva ${ }^{3}$
}

- Enviado em 08/08/2015

- Aprovado em 18/08/2015

Através dos esforços de Ernani Zétola, em conjunto com o Lions Clube São José Aeroporto e com a Prefeitura Municipal, o Museu Municipal de São José dos Pinhais, como foi nomeado primeiramente, foi fundado em 1977. Ainda sem sede própria, localizou-se por mais ou menos quatro anos na Rua Mendes Leitão, no centro da cidade. No ano de 1981, além de passar a se chamar Museu Municipal Atílio Rocco, em homenagem ao latifundiário que doou e vendeu muitas terras para a prefeitura ajudando no povoamento da cidade, a entidade passou ao Palacete Ordine, onde está atualmente. Conforme o "Primeiro Livro de Registros nos nivelamentos das ruas da cidade a cargo da fiscalização", de 1911/1912, Manoel Victorino Ordine solicitou os serviços municipais de nivelamento e medição, em 27 de maio de 1912, para "fazer edificação" em terreno com “40 metros de frente e 84,55 metros de fundos" o terreno sito à Praça Doutor Silveira da Motta, atual trecho da Rua XV de Novembro, em frente ao Museu Municipal Atílio Rocco. Tendo em vista que a legislação do período estipulava o prazo de um ano para início das obras, caso contrário o terreno tornar-se-ia devoluto ${ }^{4}$, acredita-se que a obra tenha sido iniciada ainda em 1912.

\footnotetext{
${ }^{1}$ Titulado em Conservação-Restauração pelo Ministério da Cultura (2013). Formado no curso de Gestion de Patrimoine et Collections da École du Louvre (2015). Graduado em História pela Pontifícia Universidade Católica do Paraná (2015). Especializando em História da Arte pelo Centro Universitário Claretiano. Atuou no Museu Municipal Atílio Rocco nos anos entre 2012 e 2014. Atualmente faz parte do corpo técnico do Círculo de Estudos Bandeirantes e do Centro de Memória da PUCPR. Endereço eletrônico: lucianochinda.lcd@ gmail.com.

2 Bacharel em Biblioteconomia pelas Faculdades Integradas Coração de Jesus (2007). Há sete anos atua como bibliotecário e responsável pela reserva técnica do Museu Municipal Atílio Rocco. Endereço eletrônico: vitor.carmo@sjp.pr.gov.br.

${ }^{3}$ Graduado em História pela UFPR. Endereço eletrônico:gladisson10@ gmail.com.

${ }^{4}$ SÃO JOSÉ DOS PINHAIS. Leis, Regimento, Regulamento, Resoluções, Actos e Decretos e Contractos precedida da Consolidação das Leis sobre o Governo Municipal”. Camara Municipal de São José dos Pinhaes. Typographia Max Roesner: Curityba, 1911.
} 
Destarte, ao analisar os livros de "Lançamento do imposto predial" de São José dos Pinhais, não se encontra o nome de Manoel Victorino Ordine arrolado entre os contribuintes nos livros anteriores a 1915 . Ordine paga o imposto predial no valor de $12 \$ 500$, equivalente a $5 \%$ do valor locativo anual do prédio, avaliado em 500\$000 pelo município, apenas em 18 de janeiro de 1916, relativo ao segundo semestre do exercício de 1915. Diante dos indícios, portanto, deduz-se que o imóvel que abriga atualmente o Museu Municipal de São José dos Pinhais não fora concluído, até o segundo semestre de 1915.

O prédio que abriga o Museu Municipal Atílio Rocco atualmente, portanto, foi vendido por Manoel Victorino Ordine ao Município de São José dos Pinhais, representado pelo então prefeito, João José Massaneiro, em 12 de abril de 1921, pelo valor de Cr\$19.000,00, conforme escritura pública de compra e venda lavrada nas notas do Tabelião Antonio Cesar da Rocha. Posto isto, desde 1921, portanto, o palacete passa a abrigar simultaneamente os poderes Executivo, Legislativo e Judiciário do município, bem como a Associação Comercial e Industrial, Agrícola e Prestadora de Serviços até o ano de 1981, quando a prefeitura é transferida para o atual paço municipal, na gestão do prefeito Moacir Piovesan. Em Março deste mesmo ano o prédio que já abrigou tanta história passou a acolher, também, o Museu Municipal Atílio Rocco. Antes disso, porém, o palacete onde funciona o MUMAR havia sido tombado pelo patrimônio histórico do município, por meio do Decreto Municipal n 208 de 04 de Novembro de 1980.

No ano de 2000, o Museu recebeu da Prefeitura Municipal todo o acervo do arquivo público, e este material foi devidamente quantificado e separado entre os anos de 2003 e 2005. Em 2007 teve seu espaço físico ampliado com a construção de um prédio anexo, que, no térreo, abrigava a "Cinemateca", e o piso superior era usado para exposições. Em 2010 teve aprovado seu regulamento, onde consta como missão desenvolver ações de resgate, preservação e divulgação do Patrimônio Cultural de São José dos Pinhais, tornando visível a trajetória histórica/cultural de sua sociedade. No ano de 2013, com o intuito de melhor salvaguardar seu acervo, o Museu passou por uma mudança física em sua reserva técnica, passando a locar-se no térreo do prédio anexo (antiga Cinemateca), por ser uma construção mais nova e mais moderna, e consequentemente melhor preparada para preservar o acervo da entidade.

Ainda em 2013, se deu uma parceria com a Coordenação do Sistema Estadual de Museus (COSEM), da Secretaria de Estado da Cultura do Paraná, e a base de dados de todo o trabalho de catalogação desenvolvido com o acervo migrou para o Sistema Pergamum, desenvolvido pela PUCPR, dando início à disponibilização do acervo na internet. Atualmente se tem online apenas informações e descrições de cada item do acervo. As próximas etapas compreendem um 
aprimoramento dessas informações e digitalização do acervo, para que imagens dele também sejam acessadas.

O acervo do Museu Municipal Atílio Rocco conta com mais de 6 mil peças dentre esculturas, gravuras, numismática, armas brancas, utensílios domésticos, indumentárias e objetos religiosos. Seu acervo é composto em sua maioria por peças obtidas por meio de doações de famílias tradicionais de São José dos Pinhais. Possui também um arquivo histórico com mais de 1200 fotografias, mapas e plantas, 150 encadernações de periódicos do município (como jornais das décadas de 1950, 1970, 1980, 1990 e 2000), 200 livros códices e mais de 80 mil páginas de documentos históricos. A Reserva Técnica desse acervo museológico, arquivístico e bibliográfico ficava situada no andar inferior do prédio histórico do Museu. De um modo geral, o acervo do Museu está em um bom estado de conservação e está disponível para pesquisa.

Além do trabalho de salvaguardar a história material da cidade, o Museu desenvolve uma ação muito conhecida atualmente com a Ação Educativa, através do qual recebe grupos (crianças, turistas, estudantes, famílias etc.) e faz um trabalho de educação patrimonial e explicação da história municipal através de exposições. E também, esporadicamente, apresenta programações com palestras, lançamentos de livros e atos musicais.

ENDEREÇO: Rua XV de Novembro, 1660 - Centro - São José dos Pinhais/PR CONTATO: (41) 3381-5900 / (41) 3381-5913

HORÁRIO DE FUCIONAMENTO: de terça à sexta-feira - das 09h00 às 17h00 / sábado - das $10 \mathrm{~h} 00$ às $16 \mathrm{~h} 00$

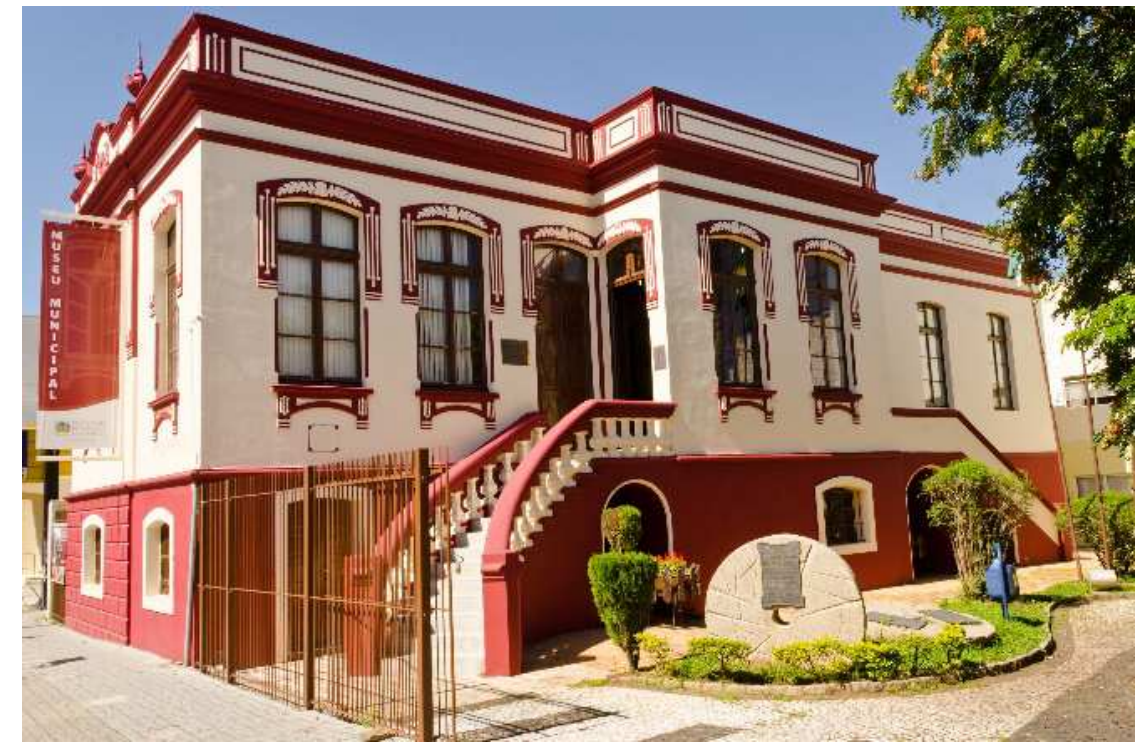

Foto acervo Museu Atílio Rocco 